\title{
Neuroprotective Effect of Alpinia galanga Against Middle Cerebral Artery Occlusion- Induced Ischemia in Rat
}

\author{
Tahereh Farkhondeh $^{1}{ }^{(D)}$, Mohsen Azimi-Nezhad ${ }^{2}$ (D), Fariborz Samini ${ }^{3}$ (D), Ali Mohammad Pourbagher- \\ Shahri 4 (iD), Saeed Samarghandian 5,* (D)

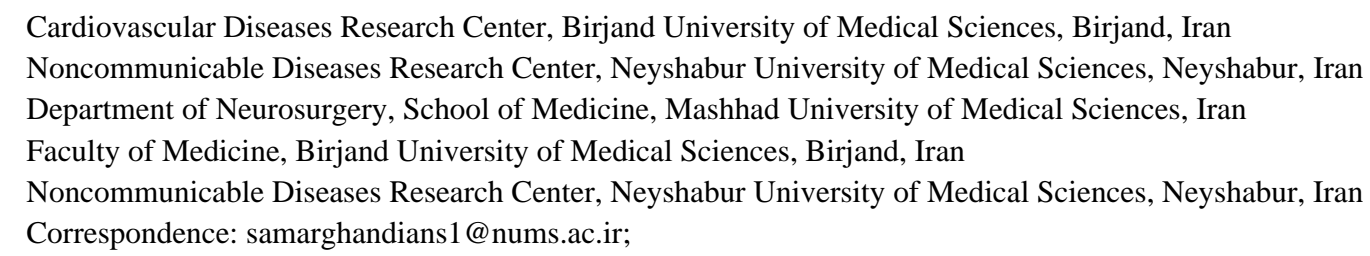

Scopus Author ID 6507632790

Received: 22.04.2020; Revised: 9.05.2020; Accepted: 10.05.2020; Published: 12.05.2020

\begin{abstract}
Alpinia galangal (A. galanga) is among the oldest traditional medications. A. galangal has important antioxidant characteristics. In the current research, we investigated the neuroprotective potential of ethanol extract of rhizomes of A. galanga in middle cerebral artery occlusion (MCAO)induced ischemia in rats. Rats were treated with A. galanga (10 and $20 \mathrm{mg} / \mathrm{kg}$, i.p.) every 24 hours for 3 days after MCAO for 45 minutes. The behavioral impairments in rotarod performance, Angle board, and Grip test were decreased significantly in A. galanga treated rats compared to the sham-operated rats. The ischemic rats treated with A. galanga significantly improved neurobehavioral performance compared to the untreated ischemic rats. Furthermore, A. galangal treatment reduced the contralateral cortical infarct area in the MCAO rats. Our results indicated the neuroprotective properties of $A$. galanga in the rat model of cerebral ischemia.
\end{abstract}

Keywords: Alpinia Galanga; Cerebral Ischemia; locomotor Functions; Middle Cerebral Artery Occlusion; Neuroprotection.

(C) 2020 by the authors. This article is an open access article distributed under the terms and conditions of the Creative Commons Attribution (CC BY) license (https://creativecommons.org/licenses/by/4.0/).

\section{Introduction}

Neurological deficit following vascular-related cerebral damage to the central nervous system that has an acute onset is called a stroke. As the population age the incidence of stroke increases [1]. The incidence of stroke is about 17 million cases a year worldwide. In the list of worldwide leading causes of death, the stroke is placed only after coronary artery diseases [1]. Stroke is either ischemic (85\%) or hemorrhagic (15\%) [1]. Disruption of cerebral blood supply for a particular duration results in transient focal cerebral ischemia. The ischemia/reperfusion (I/R) injuries damage the hemostasis of ionic gradients inside and outside the cells, which demonstrate itself as calcium and sodium accumulation. Furthermore, the $\mathrm{pH}$ level is decreased; mitochondrial function becomes disrupted; DNA damage occurs due to calciumdependent enzymatic reactions; excessive free radicals are generated; lipid peroxidation is triggered, and ultimately cell apoptosis happens $[2,3]$.

The brain is a vulnerable organ towards free radicals. This vulnerability comes several factors, including a high amount of polyunsaturated fatty acids, accelerated oxidative metabolic activity along with a low endogenous antioxidant potential as well as insufficient neuronal cell 
repair capacity [4]. The first step in cerebral ischemia treatment is restoring cerebral blood flow and cerebral reperfusion. Despite being a critical step in alleviating the ischemic damage of the brain, during reperfusion, reactive oxygen species (ROS) generate at excessive amounts from damaged cells results to further cerebral injury [5]. Current treatments for ischemic stroke are based on recanalization of the occluded artery to restore perfusion to the tissue that remains salvageable [6]. The recanalization therapies only modulate cerebral blood flow and do not affect the neurons directly. Currently, there is no therapeutic agent that could directly interact with neuronal and cellular aspects of the ischemic injury. To this matter, numerous studies have investigated different agents in different experimental and clinical conditions. Traditional medicine had been using natural products and herbal extracts as therapeutic and preventive modalities for diseases since time immemorial [7]. An ongoing growth in the field of herbal medicine has been started from a few decades ago which commercialized its use in the developing and developed countries. Recent studies have been performed in search of the ROS scavengers for a therapeutic strategy for neurological diseases, including stroke. To this end, several natural agents with antioxidants characteristics had been demonstrating neuronal protection against cerebral I/R injury [8-11].

Alpinia Galanga (A.galanga) belongs to the family of "Zingiberaceae" and has been used as a food additive from centuries ago. It is called by several other names, including Siamese ginger, Thai ginger, and greater galangal. It is a rhizomatous herb, native to Southeast Asia. The rhizome of A. galanga has been shown to have antimicrobial, hepato-protective, antiHIV, immunomodulatory, anti-diabetic, and anti-ulcer properties (extensively reviewed by [12]). The presence of several constituents, including viz. 1, 8-cineole, 4-allyl phenylacetate, and $\beta$-bisabolene in the essential oil of A. galanga, produce considerable antioxidant and antimicrobial potential [13].

Previous studies have shown that treatment with A. galanga attenuated cerebral $\mathrm{I} / \mathrm{R}$ injury and oxidative stress in the hippocampus [14]. Here, we examined the neuroprotective potentials of A.galanga in a transient middle cerebral artery occlusion (MCAO) rat model by determining and analyzing its effects on the brain infarct volume and behavioral functions.

\section{Materials and Methods}

\subsection{Extract preparation.}

Alpinia galanga rhizomes were procured from the local market of Mashhad, Iran, and authentically identified in the Department of Botony, Ferdowsi University, Mashhad, Iran. The extract was prepared from dried A. galanga rhizome using $90 \%$ ethanol (v/v) in the water at a solid-to- solvent ratio of 1:10.

\subsection{Experimental animals.}

Male Wistar rats weighing 250-300g were chosen for this study. The rats were kept in standard animal house conditions. Standard laboratory chow and water were fed to the animals. The acclimatization of the animals started before starting the MCAO experiment.

\subsection{Induction of ischemia.}


Rats underwent transient ischemia by the method of left MCAO using the intraluminal filament model. The MCAO procedure was performed based on the method described by Longa et al. (1989). Animals underwent transient MCAO for 45 minutes, followed by 72-hour reperfusion.

The same surgical procedure without the middle cerebral artery occlusion was performed in the sham-operated animals.

\subsection{Experimental groups and drug treatment.}

The drugs (A. galangal extract or vehicle) were injected intraperitoneally (i.p.) with at the following times: $0 \mathrm{~h}, 24 \mathrm{~h}, 48 \mathrm{~h}$, and $72 \mathrm{~h}$ after the MCAO.

Animals were divided into 5 groups of 8 rats each. Groups of rats were as follow (Group 1) Sham(5): sham-operated rats receiving A.galanga (5 mg/kg of body weight, i.p.); (Group 2) Sham(10): sham-operated rats receiving A.galanga (10 mg/kg of body weight, i.p.); (Group 3) Vehicle: MCAO-operated rats receiving only normal saline (same volume of A. galangal in treatment groups); (Group 4) A. galanga(5): MCAO-operated rats receiving A.galanga (5 $\mathrm{mg} / \mathrm{kg}$ of body weight, i.p.); and (Group 5) A. galanga(10): MCAO-operated rats receiving A.galanga (10 mg/kg of body weight, i.p.).

\subsection{Behavioral studies.}

Behavioral studies in the vehicle- and A. galanga-treated and sham groups were carried out at $0,24,48$, and $72 \mathrm{~h}$ after the MCAO. Behavioral assessment was performed by conducting the rotarod, Angle board, and grip test.

\subsection{Rotarod test.}

It is used for assessing motor performance in experimental rats and mice. On a rotating rod, animals keep their balance. The latency to fall from the rod is recorded as the endpoint measure. The rotation speed of the rod is either constant or accelerated. Here, rats were trained for being able to remain on the rod for $120 \mathrm{~s}$, in two trials with a rotation speed of 16 rounds per minute (RPM). At 24, 48, and $72 \mathrm{~h}$ after the MCAO operation, the rotarod test was performed with the speed of 16 RPM for $120 \mathrm{~s}$ for two trials. To obtain the best results, each rat went on five separate trials for achieving the most accurate latency to fall.

\subsection{Angle board test.}

At first, rats were trained to remain on a $60^{\circ}$-angled incline board for $120 \mathrm{~s}$ for two trials. At 24, 48, and $72 \mathrm{~h}$ after the MCAO operation, the angle board test was performed on a $60^{\circ}$-angled incline plane for $120 \mathrm{~s}$. To obtain the best results, each rat went on five separate trials for achieving the most accurate time for standing on the inclined angle board.

\subsection{Grip test.}

The grip test evaluates the muscular strength of the limbs. For the sake of this test, while animals grip a grid surface, the duration of their action is measured; also, when they grip a metal bar, the strength they use is measured as well [15]. Grip test was performed by lifting the rats by their tails until their front paws were at the same height as the bar. After reaching the bar by their first pawns, quality of grip strength (i.e., symmetric, tight grip, resistance against 
the investigator pull) was checked visually. To being able to hold their grip on the bar for $60 \mathrm{~s}$ for two trials, the animals were trained as many times as they needed. At 24, 48, and $72 \mathrm{~h}$ after the MCAO operation, the grip test was performed for each rat. Five separate trials were conducted for each rat to determine the most accurate time of holding on to the bar.

\subsection{Measurement of infarct volume.}

Seventy-two hours after MCAO, an overdose of chloral hydrate was used to sacrifice the rats. Removing brains was performed quickly; then, it was chilled in a solution of ice-cold saline for a total of 5 minutes. After chilling, 8 slices with 2 millimeters thickness were obtained from coronally sectioned brains. The slicing was done using a brain slicer (brain matrix) starting from the frontal pole. From the middle of the brain, 6 sections were chosen and stained for 30 minutes with 2\% 2,3,5triphenyltetrazolium chloride (TTC, Merck, Germany) in normal saline at $37^{\circ} \mathrm{C}$. Then, a digital camera (Sony camera, Japan.) interfaced to a computer, was used for imaging the obtained sections. The images were quantified using an image analyzing program (UTHSCSA Image Tool 3.00 for Windows software.).

\subsection{Statistical analysis.}

Values are showed as mean \pm standard deviation (SD). Graphpad Prism 5.0 (GraphPad Software, USA) was used for statistical analysis. One-way analysis of variance was used where appropriate. The post-doc comparison was performed by applying Tukey- Kramer's Multiple Comparison Test. The levels of $\mathrm{P}<0.05$ were considered for determining a significant difference.

\section{Results and Discussion}

\subsection{Behavioral evaluation.}

\subsubsection{Rotarod performance.}

The latency to fall in the rotarod test for the vehicle control group at the first and second days after the MCAO was significantly decreased compared to the sham group. Treatment with A. galanga $(10 \mathrm{mg} / \mathrm{kg})$ in the MCAO rats significantly increased the latency to fall in comparison to the vehicle rats at first and second day after occlusion $(\mathrm{p}<0.01$ and $\mathrm{p}<0.05$, respectively) (Figure 1).

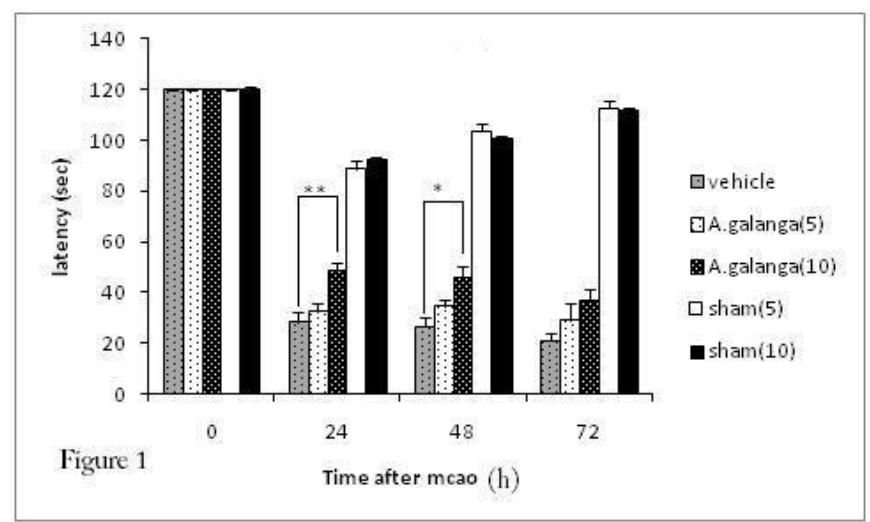

Figure 1. The rotarod test results over a 3-day post-ischemia period.

3.1.2. Angle board test. 
The duration of stay during the angle board test was decreased in the vehicle control group compared to the sham group. Treatment with A. galanga $(10 \mathrm{mg} / \mathrm{kg})$ in rats with MCAO caused significant protection in the total period of stay on the angel board at first, the second and third day after occlusion ( $\mathrm{p}<0.01, \mathrm{p}<0.001$ and $\mathrm{p}<0.001$, respectively). The $10 \mathrm{mg} / \mathrm{kg}$ dose of A. galanga increased in the period of stay on the inclined plane, which was significantly higher compared to the low dose of A. galanga ( $5 \mathrm{mg} / \mathrm{kg}$ ) (Figure 2).

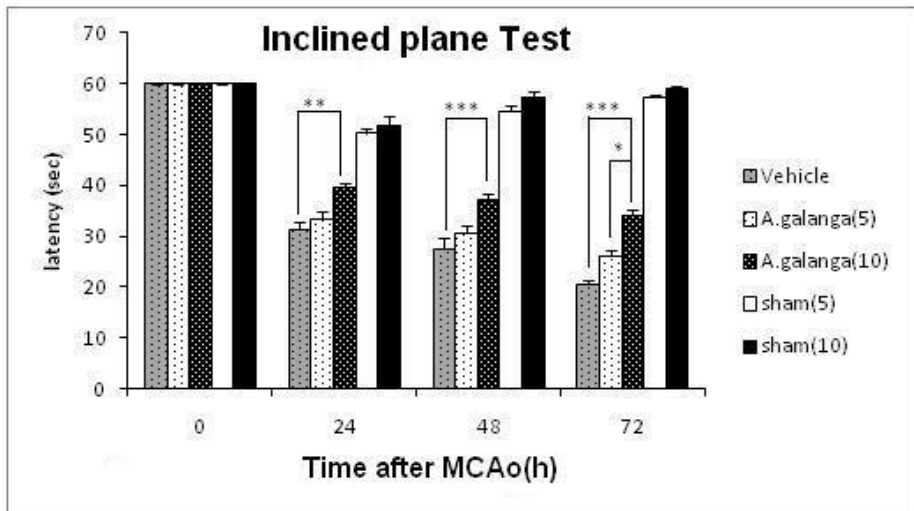

Figure 2. The angle board test results over a 3-day post-ischemia period.

\subsubsection{Grip test.}

The duration of remaining on the bar at the first, second, and third days after MCAO in the vehicle control group was significantly lower compared to the sham groups. In the A. galanga treated group $(10 \mathrm{mg} / \mathrm{kg})$, the duration of remaining on the bar significantly increased at first, second, and third days after MCAO compared to the vehicle control group. $(\mathrm{p}<0.001)$ (Figure 3).

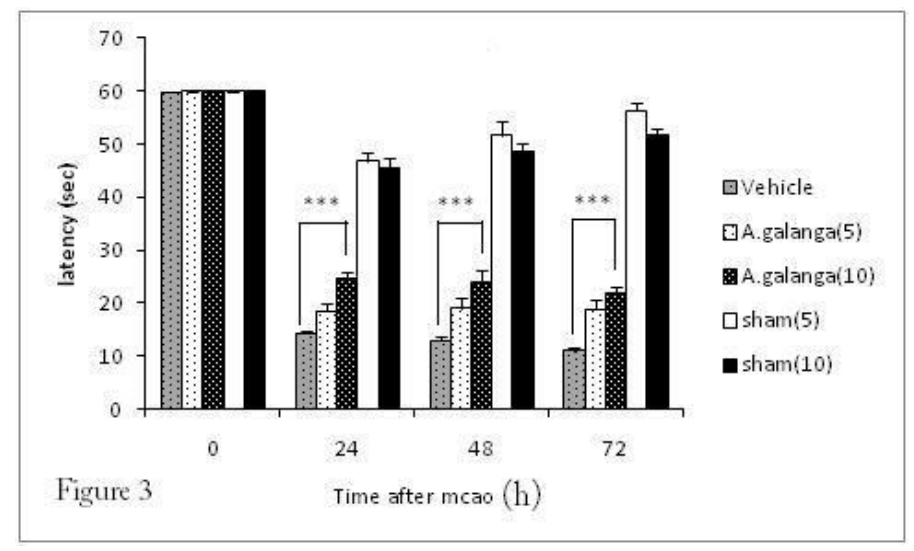

Figure 3. The grip test results over a 3-day post-ischemia period.

\subsection{Ischemic damage.}

The obtained brain sections extracted $72 \mathrm{~h}$ after the MCAO, were histologically examined. The vehicle control rats had demarcated contralateral hemispheric infarction (455 $\mathrm{mm}^{3}$ ). Interestingly, A. galanga treatment (5 and $10 \mathrm{mg} / \mathrm{kg}$ ) in rats with MCAO had contralateral hemispheric infarction volumes of 380 and $190 \mathrm{~mm}^{3}$, respectively. As expected, the sham-operated rats showed no ischemic damage in their brain sections (Figure 4). 


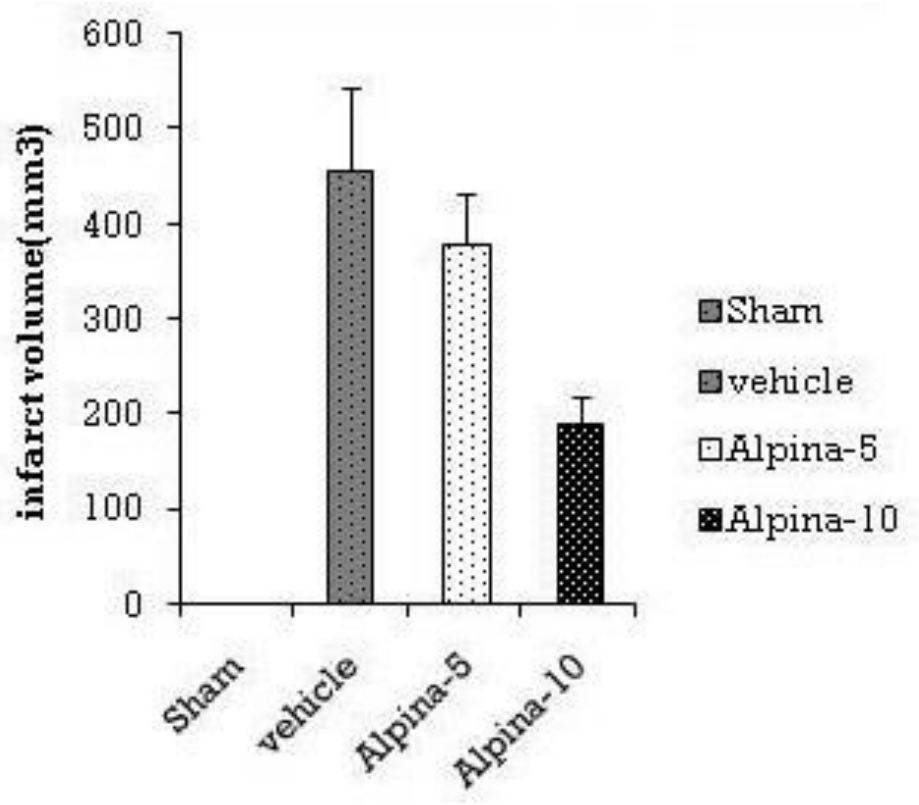

Figure 4. Volumes of the ischemic lesion $72 \mathrm{~h}$ post-ischemia time.

\subsection{Discussion.}

In this study, we demonstrated that cerebral ischemia following MCAO for 45 minutes in the rats resulted in impaired behavioral functions that were significantly improved upon intraperitoneal administration of A. galangal at doses of 5 and $10 \mathrm{mg} / \mathrm{kg}$. Also, the contralateral hemispheric infarction volumes were decreased in rats treated with A. galanga compared to the rats who did not receive treatment. In experimental studies, the most used model for ischemic stroke is the MCAO model performed in rats [16]. The MCAO model has the advantages of being reproducible and similar to ischemic injuries found in humans [17]. It has been observed that as early as $1 \mathrm{~h}$ after reperfusion after MCAO, the formation of ROS is increased [18]. The ischemic strokes in humans have the same pattern of ROS's increase [19]. The MCAO method of inducing the infarction and its duration successfully generated an experimental cerebral ischemia condition in this study.

Clinical and experimental studies have shown that global cerebral ischemia subjects have impaired memory and cognition functions along with pathological damages in different brain regions [20]. A significant decrease in the locomotor activity after 2 weeks from global cerebral ischemia has been reported [21]. These effects demonstrated themselves in locomotor activity tests. Consistent with the previous studies, a decrease in locomotor activity was observed in our study after 45 minutes of global cerebral ischemia. It worth mentioning that manifestation of locomotor deficits in the animal model varies from those observed in humans so, trying to reproduce the exact signs exhibited by patients exactly is not necessarily practical. To overcome that, selecting useful tests for assessing motor pathways through their related motor anomalies are more practical [15]. For assessing motor coordination and balance following cerebral damage, the rotarod test is one of the most used ones. For measuring sensorimotor impairments in animal models for various neurological diseases, including amyotrophic lateral sclerosis, cerebellar ataxia, traumatic brain injury, and stroke, the rotarod test has shown considerable sensitivity [22-25].

As mentioned before, the rod in the rotarod test is either rotate at a constant or an accelerating speed. A problem with accelerating rod is fatigue that thought to influence the results, whereas, in constant speed, final results are thought to reflect biological changes 
influencing the motor coordination and balance with more sensitivity. Considering that we used a rod with constant speed to have a better understanding of ischemic injury effects on the motor functions. The impaired motor function following I/R cerebral injury demonstrated itself in the rotarod performance of the MCAO rats in this study. Rats with focal cerebral ischemia have shown decreased latency to fall in their rotarod test [26].

The A. galangal treated rats indicated an ameliorative performance in the rotarod test, demonstrating as a significant increase in their latency to fall compared to the vehicle control group. These differences represent the preventive effects of A. galanga against I/R injuryinduced impairment of locomotor functions.

The angle board and grip test are also a useful test for assessing motor function in animal models. The I/R injury affected the angle board and grip test performance like the rotarod test by decreasing the latency time to the endpoint of the test. In this study, the vehicle control (MCAO rats) showed decreased latency time in both the angle board and grip test. The neuroprotective effects of A. galanga demonstrated itself through a significant amelioration of decreased latency time of performance of the angle board and grip tests.

So far, we discussed the gross neuroprotective effects of A. galanga; however, cellular or molecular levels of A. galanga's mechanism did not. In normal conditions, endogenous superoxide dismutase (SOD) inactivates the $\mathrm{O}_{2}^{-}$. At the same time, catalase (CAT) and the glutathione peroxidase (GPx) are busy with decomposing the $\mathrm{H}_{2} \mathrm{O}_{2}$ into water $[27,28]$. However, during cerebral I/R injury, the activity of SOD, CAT, and GSH are decreased, and ROS cannot be readily scavenged.

In cerebral ischemia, free radicals, oxygen, and hydroxyl radicals are generated extensively [29]. Also, it has been established that in the reperfusion phase generation of free radicals are more enhanced [26]. The high amounts of free radical species generated in the ischemia and reperfusion phases cause more cerebral injuries [30]. So, either preventing the oxidative stress or lowering it or both, can serve as a therapeutic strategy for the vicious circle of cerebral I/R injury. The mentioned antioxidative strategies have been demonstrated in the natural antioxidants from plants. The attracted attention towards natural antioxidants is mainly due to their safety and potential nutritional and therapeutic effects. Antioxidant characteristics of the natural and herbal products make them able to serve as therapeutic agents in managing cerebral ischemia [29]. The antioxidant activities of A. galanga and its extracts are well documented. Antioxidant activities of A. galanga have been reported to be stronger in its essential oil with an $\mathrm{IC}_{50}$ value of $550 \mathrm{mg} / \mathrm{ml}$ [31]. The dichloromethane (DCM) and methanol extract of rhizome of A. galanga have shown dose-dependent antioxidant activity. Jitoe and his co-workers showed that the antioxidant activity of a $1 \%(\mathrm{w} / \mathrm{v})$ acetone extract of A. galanga in $99.5 \%$ ethanol was stronger than that of $\alpha$-tocopherol [32]. In this study, the ethanolic extract of A. galanga was used and showed the ability to improve the neurological function in the MCAO rats.

A therapeutic agent with an efficacious intervention can reduce neurologic deficits of stroke. Here, the neurological and functional measuring modalities were employed to study the effects of A. galanga intervention on transient focal cerebral ischemia outcome. Our data showed that treatment with 5 and $10 \mathrm{mg} / \mathrm{kg}$ A. galanga extracts had significant protection against functional deficits and concomitantly reduced the cerebral infarction after cerebral I/R injury. 


\section{Conclusion}

In summary, the data of this study showed that intraperitoneal treatment with the appropriate doses of A. galanga decreased the ischemic cell damage and neurological function deficits. Multiple mechanisms of action, including antioxidation, can be linked to beneficial effects of A. galanga.

\section{Funding}

This research received no external funding.

\section{Acknowledgments}

The authors would like to thank the research affairs of the Neyshabur University of Medical Sciences for financially supporting this work.

\section{Conflicts of Interest}

The authors declare no conflict of interest.

\section{References}

1. Yazgan, B.; Baltaci, A. K.; Mogulkoc, R.; Avunduk, M. C.; Sahna, E. Effect of zinc sulfate supplementation on metallothionein levels in rat heart tissue with induced ischemia-reperfusion injury. Biointerface Research in Applied Chemistry, 2018, 8(3), 3193-3196.

2. Gad, H.; Khan, A.; Akhtar, N.; Kamran, S.; El-Sotouhy, A.; Dargham, S.R.; Petropoulos, I.N.; Ponirakis, G.; Shuaib, A.; Streletz, L.J.; Malik, R.A. Corneal nerve and endothelial cell damage in patients with transient ischemic attack and minor ischemic stroke. PLoS One. 2020, 15, e0231987, https://doi.org/10.1371/journal.pone.0213319.

3. Duman, A.; Mogulkoc, R.; Baltaci, A. K.; Sivrikaya, A. The effect of 3',4'-dihydroxyflavonol on plasma oxidant and antioxidant systems in testis ischemia-reperfusion injury in rats. Biointerface Research in Applied Chemistry, 2018, 8(4), 3441-3445.

4. Pena-Bautista, C.; Baquero, M.; Vento, M.; Chafer-Pericas, C. Free radicals in Alzheimer's disease: Lipid peroxidation biomarkers. Clinica chimica acta; international journal of clinical chemistry 2019, 491, 85-90, https://doi.org/10.1016/j.cca.2019.01.021.

5. Piccardi, B.; Arba, F.; Nesi, M.; Palumbo, V.; Nencini, P.; Giusti, B.; Sereni, A.; Gadda, D.; Moretti, M.; Fainardi, E.; Mangiafico, S.; Pracucci, G.; Nannoni, S.; Galmozzi, F.; Fanelli, A.; Pezzati, P.; Vanni, S.; Grifoni, S.; Sarti, C.; Lamassa, M.; Poggesi, A.; Pescini, F.; Pantoni, L.; Gori, A.M.; Inzitari, D. Reperfusion Injury after ischemic Stroke Study (RISKS): single-centre (Florence, Italy), prospective observational protocol study. BMJ Open 2018, 8, e021183-e021183.

6. Powers, W.J.; Rabinstein, A.A.; Ackerson, T.; Adeoye, O.M.; Bambakidis, N.C.; Becker, K.; Biller, J.; Brown, M.; Demaerschalk, B.M.; Hoh, B.; Jauch, E.C.; Kidwell, C.S.; Leslie-Mazwi, T.M.; Ovbiagele, B.; Scott, P.A.; Sheth, K.N.; Southerland, A.M.; Summers, D.V.; Tirschwell, D.L. Guidelines for the Early Management of Patients With Acute Ischemic Stroke: 2019 Update to the 2018 Guidelines for the Early Management of Acute Ischemic Stroke: A Guideline for Healthcare Professionals From the American Heart Association/American Stroke Association. Stroke 2019, 50, e344-e418.

7. Karbwang, J.; Crawley, F.P.; Na-Bangchang, K.; Maramba-Lazarte, C. Herbal Medicine Development: Methodologies, Challenges, and Issues. Evid Based Complement Alternat Med 2019, 2019, https://doi.org/10.1155/2019/4935786.

8. Rani, S.; Gahlot, K.; Kumar, A. Experimental evidences of antidiabetic activity of aqueous extract of Cressa cretica L. on streptozotocin induced diabetes in rats. Letters in Applied NanoBioScience. 2020, 9 (1), 774 778.

9. Mollaamin F. What is the effect of body's chemical messengers in the brain. Letters in Applied NanoBioScience. 2019, 8(3), 613 - 618.

10. Bavarsad, K.; Barreto, G.E.; Hadjzadeh, M.A.; Sahebkar, A. Protective Effects of Curcumin Against Ischemia-Reperfusion Injury in the Nervous System. Molecular neurobiology 2019, 56, 1391-1404, https://doi.org/10.1007/s12035-018-1169-7.

11. Gaire, B.P. Herbal Medicine in Ischemic Stroke: Challenges and Prospective. Chinese journal of integrative medicine 2018, 24, 243-246, https://doi.org/10.1007/s11655-018-2828-2. 
12. Verma, R.K.; Garima, M.; Pradeep, S.; Jha, K.; Khosa, R.J.D.P.S. Alpinia galanga-an important medicinal plant: a review. 2011, 2, 142-154.

13. Raina, A.P.; Verma, S.K.; Abraham, Z. Volatile constituents of essential oils isolated from Alpinia galanga Willd. (L.) and A. officinarum Hance rhizomes from North East India. Journal of Essential Oil Research 2014, 26, 24-28, https://doi.org/10.1080/10412905.2013.822430.

14. Mundugaru, R.; Sivanesan, S.; Udaykumar, P.; DJ, V.; Prabhu, S.N.; Ravishankar, B.J.I.J.O.P.E.; Neuroprotective Functions of Alpinia galanga in Forebrain Ischemia Induced Neuronal Damage and Oxidative Insults in Rat Hippocampus. 2018, 52, S77-S85, https://doi.org/10.5530/ijper.52.4s.79.

15. Brooks, S.P.; Dunnett, S.B. Tests to assess motor phenotype in mice: a user's guide. Nat Rev Neurosci 2009 , 10, 519-529, https://doi.org/10.1038/nrn2652.

16. Belayev, L.; Busto, R.; Zhao, W.; Ginsberg, M.D. HU-211, a novel noncompetitive N-methyl-D-aspartate antagonist, improves neurological deficit and reduces infarct volume after reversible focal cerebral ischemia in the rat. Stroke 1995, 26, 2313-2319.

17. Hermann, D.M.; Popa-Wagner, A.; Kleinschnitz, C.; Doeppner, T.R. Animal models of ischemic stroke and their impact on drug discovery. Expert opinion on drug discovery 2019, 14, 315-326, https://doi.org/10.1080/17460441.2019.1573984.

18. Peters, O.; Back, T.; Lindauer, U.; Busch, C.; Megow, D.; Dreier, J.; Dirnagl, U. Increased formation of reactive oxygen species after permanent and reversible middle cerebral artery occlusion in the rat. J Cereb Blood Flow Metab 1998, 18, 196-205, https://doi.org/10.1097/00004647-199802000-00011.

19. Zou, P.; Liu, X.; Li, G.; Wang, Y. Resveratrol pretreatment attenuates traumatic brain injury in rats by suppressing NLRP3 inflammasome activation via SIRT1. Molecular medicine reports 2018, 17, 3212-3217, https://doi.org/10.3892/mmr.2017.8241.

20. Georgakis, M.K.; Duering, M.; Wardlaw, J.M.; Dichgans, M. WMH and long-term outcomes in ischemic stroke: A systematic review and meta-analysis. Neurology 2019, 92, e1298-e1308, https://doi.org/10.1212/wnl.0000000000007142.

21. Milot, M.R.; Plamondon, H. Time-dependent effects of global cerebral ischemia on anxiety, locomotion, and habituation in rats. Behav Brain Res 2009, 200, 173-180, https://doi.org/10.1016/j.bbr.2009.01.009.

22. Ritzel, R.M.; Patel, A.R.; Spychala, M.; Verma, R.; Crapser, J.; Koellhoffer, E.C.; Schrecengost, A.; Jellison, E.R.; Zhu, L.; Venna, V.R.; McCullough, L.D. Multiparity improves outcomes after cerebral ischemia in female mice despite features of increased metabovascular risk. Proc Natl Acad Sci U S A 2017, 114, E5673E5682, https://doi.org/10.1073/pnas.1607002114.

23. Adwanikar, H.; Noble-Haeusslein, L.; Levin, H.S. Traumatic brain injury in animal models and humans. In: Animal Models of Behavioral Analysis. Springer: 2011; pp. 237-265.

24. Hamm, R.J.; Pike, B.R.; O'Dell, D.M.; Lyeth, B.G.; Jenkins, L.W. The rotarod test: an evaluation of its effectiveness in assessing motor deficits following traumatic brain injury. J Neurotrauma 1994, 11, 187-196, https://doi.org/10.1089/neu.1994.11.187.

25. iu, J.; Zhou, G.; Kolls, B.J.; Tan, Y.; Fang, C.; Wang, H.; Laskowitz, D.T. Apolipoprotein E mimetic peptide $\mathrm{CN}-105$ improves outcome in a murine model of SAH.. Stroke Vasc Neurol 2018, 3, 222-230, https://doi.org/10.1136/svn-2018-000152.

26. Callaway, J.K.; Knight, M.; Castillo-Melendez, M.E.; Watkins, D.; Beart, P.M.; Jarrott, B. Am36, a novel neuroprotective agent, reduces neuronal damage in a middle cerebral artery occlusion model of stroke in conscious rats. In: Proceedings of ASCEPT. 1998; pp. 43.

27. Bhattacharyya, A.; Chattopadhyay, R.; Mitra, S.; Crowe, S.E. Oxidative stress: an essential factor in the pathogenesis of gastrointestinal mucosal diseases. Physiol Rev 2014, 94, 329-354, https://doi.org/10.1152/physrev.00040.2012.

28. Schrader, M.; Fahimi, H.D. Peroxisomes and oxidative stress. Biochim Biophys Acta 2006, 1763, 1755-1766, https://doi.org/10.1016/j.bbamcr.2006.09.006.

29. Pierre, S.; Jamme, I.; Droy-Lefaix, M.T.; Nouvelot, A.; Maixent, J.M. Ginkgo biloba extract (EGb 761) protects Na,K-ATPase activity during cerebral ischemia in mice. Neuroreport 1999, 10, 47-51, https://doi.org/10.1097/00001756-199901180-00009.

30. Lin, L.; Wang, X.; Yu, Z. Ischemia-reperfusion Injury in the Brain: Mechanisms and Potential Therapeutic Strategies. Biochem Pharmacol (Los Angel) 2016, 5, 213, https://doi.org/10.4172/2167-0501.1000213.

31. Rana, V.; Verdeguer, M.; Blázquez, M. GC and GC/MS Analysis of the Volatile Constituents of the Oils of Alpinia galanga (L.) Willd and A. officinarum Hance Rhizomes. Journal of Essential Oil Research 2010, 22, https://doi.org/10.1080/10412905.2010.9700388.

32. Si, W.; Chen, Y.P.; Zhang, J.; Chen, Z.Y.; Chung, H.Y. Antioxidant activity of tropical ginger extracts and analysis of the contained curcuminoids. Antioxidant activities of ginger extract and its constituents toward lipids. Food Chemistry 2018, 239, 1117-1125, https://doi.org/10.1016/j.foodchem.2017.07.055. 